\title{
Evaluation of municipal waste incinerators (MWI) site selection based on full cost accounting using GIS tools: a case study in Beijing, China
}

\author{
Chang Zhao \\ School of Environment, Renmin University, Beijing 100000, China; \\ 1804097211@qq.com
}

Keywords: Site selection, municipal waste incinerators, external cost, ArcGIS, model builder.

\begin{abstract}
A Geographic Information System (GIS) is used as a decision-making tool for site selection in this research. Many factors are related to the site selection of Municipal waste incinerators (MWI) due to the external costs. Consequently, a site selection model is built to help regulators to choose suitable sites for MWIs. To simplify the process and reduce human errors, an automatic model built by Model Builder of ArcGIS is used in this study. A choice has been made among the MWIs planned to select a proper one based on health, transportation and operation costs. This paper presents a model that could increase the success and eliminate possible wrong justifications in the management of MWIs in large cities.
\end{abstract}

\section{Introduction}

How to dispose municipal waste is becoming a serious question for China's developed cities. A statistic shows that when every 500t waste is generated in the world, 210t comes from China. Comparing with waste landfills and composting, waste incineration is more effective because of a few advantages, such as occupying comparatively less space, decreasing the volume of waste and generating electricity [1].Restricted to limited land, China's large cities prefer to choose incineration to dispose waste, up to the present, there are 3 incinerators already built and 8 plants to be built up to 2018 in Beijing. As waste combustors being treated as the most serious resources of dioxins [2], a phenomenon "not-in-my-backyard (NIMBY)" is initiated, site selection of MWIs should be considered carefully [3]. Researches on animals show that dioxins cause damage to various organs [4]. The biological Half-life of dioxins is approximately 7-11 years. Impacts of dioxins to humans may continue as long as the earth exists. The ingestion of food contains dioxins such as meat, fish or breast milk is the dominate way of exposure [5]. According to an experiment of an MWI in Zhejiang, China, the estimated dietary intake for local residents is approximately 3.5 -fold greater than the standard (70 pg TEQ (kg bw) -1 month-1) which is set by JECFA, indicating high risk on the health of local residents near MWIs[6].

It is estimated that, the total capacity of the three incinerations is 1 million and 873 thousand ton, and the per capita is $0.949 \mathrm{~kg}$ of each person, if all municipal waste generated are combusted, waste generated by 5 million 408 thousand people can be disposed by all the three incinerations in 2015 . Accordance to the relevant provisions of the government, municipal solid waste of Beijing will be enforced to classify since 2018. Supposing that after the implementation of compulsory classification, the per capita could be reduced to $0.287 \mathrm{~kg}$, the same of that of Taipei, the existing three incinerators can carry daily waste incineration of $82.4 \%$ of residents in Beijing. Supposing that the population of Beijing would reach 23 million in 2020 , one more incineration plant with capacity of $1500 \mathrm{t} / \mathrm{d}$ is enough to serve the whole city. Therefore, in the case of waste reduction, $2 / 3$ of the proposed 11 incinerators are facing the risk of being idled.

A Geographical Information System (GIS), which is designed to store, retrieve, analyze, and map geographical data, is widely used for locating problems. A discussion about how GIS contribute to the field location science has been developed in the past few years [7, 8]. Examples of using the combination of a location selection model into a GIS framework could be found in many researches $[9,10]$.The model builder tool in GIS, which has first been developed in ERSI company and can be 
used to generate recyclable models [11], brings great convenience to users that do not major in this field, it's a powerful tool as it allows secondary advanced changes easily and realize a complicated model [12].

Through the evaluation of the model generated in this study about the site selection of municipal solid waste incineration plants, the site of 8 incineration plants to be built was evaluated to choose a proper one and the remaining incineration plant construction plans would be cancelled.

\section{Methodology}

\subsection{Study area and preliminary analysis.}

Beijing, which is the capital city of China with an area of 16410 square kilometers and a population of more than 21 million is chosen as the case city. It stretches from latitude $39.4^{\circ} \mathrm{N}$ to $41.6^{\circ} \mathrm{N}$ and from longitude $115.7^{\circ} \mathrm{E}$ to $117.4^{\circ} \mathrm{E}$. Locations of three completed MWIs are marked with triangles, the proposed eight ones use circulars to represent (fig.1 (A)). The constructions of some domestic incinerators are relatively close, which may increases health risks of some areas.

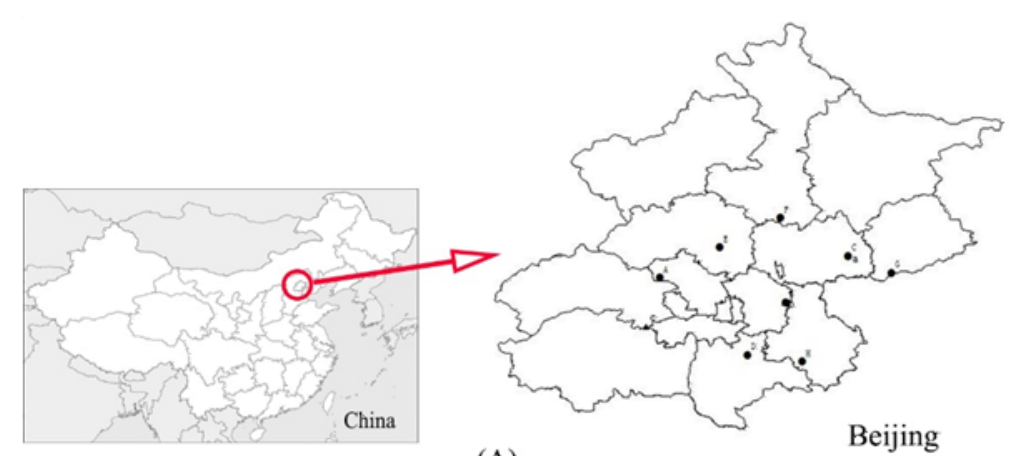

(A)

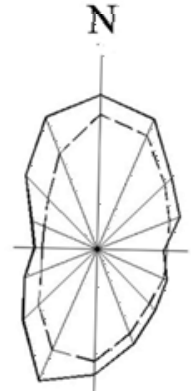

(B)

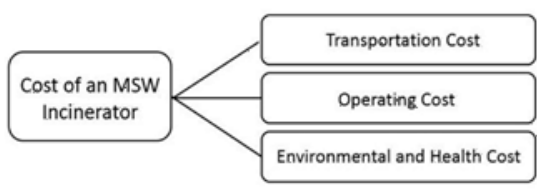

(C)

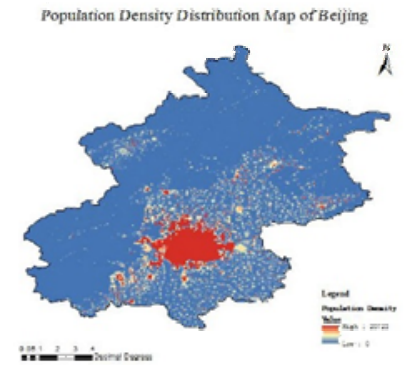

(D)

Fig.1 Geographical location of Beijing, China, leading wind chart, population density map of Beijing and analysis method in this study are introduced.

Considering the exposure of dioxins to air, water and food, the distance between the site and residential areas, cultivated land and rivers are mainly considered. Generally speaking, enterprises with severe air pollution in cities should be placed at the windward side of the minimum wind frequency. As is showed in the wind rose map of Beijing in fig.1 (B), the MWI is suitable for the east or west of Beijing. In addition, due to the characteristics of dioxin like substances, MWIs should be built far from arable land and rivers.

Model builder which allows users to make models using all ArcGIS packages is used for this research. The starting point of model is basic data on the distribution of rivers, settlements, and cultivated land, which are get from official website of the National Bureaus. The population density map of Beijing used in the model is drawn from the 2010 census data. In addition, the coordinates of the incinerators are also parameters that are needed in the model.

\subsection{Model Development.}

Social cost, which is distinguished from "private cost", was firstly put forward in 1819[13]. Negative external costs may lead to an overproduction in a free market. External cost means costs that 
may affect stakeholders that do not choose to get the benefit [14]. As to the plants with serious air pollution, external costs are involved, overall costs and benefits should be valued. Considering the actual situation, environmental and health cost, transportation cost and operating costs are involved in the model.

(1) Environmental and Health cost Analysis

As to food produced near the incinerators, the amount of dioxin is several times higher than the concentration of food purchased in supermarkets randomly [6]. As studies show that the exposure pathways of dioxins are food and drinking water, environmental and health costs is measured by the distance between the sites selected and cultivated land, river and residential area. Although China's site requirements for incineration plants is not less than $500 \mathrm{~m}$ from the residential areas, according to a Japanese research, the death rate from cancer causing by dioxins is $42.1 \%$ within $1.2 \mathrm{~km}$ from the incinerator, more than twice as much as $20.4 \%$, at about $1.2 \mathrm{~km}$ away. Considering the multiple exposure pathways of dioxins, a buffer of $1.5 \mathrm{~km}$ is set up in the residential area and around the cultivated land. Take into account the impact of pollutants to the river, and set $1 \mathrm{~km}$ buffer area around the river. Buffers drawn based on each of the three kind of exposure pathways as shown in fig.2 (A). On this foundation, the next step is to screen the region with a population density of less than or equal to 8000 persons per square kilometer.

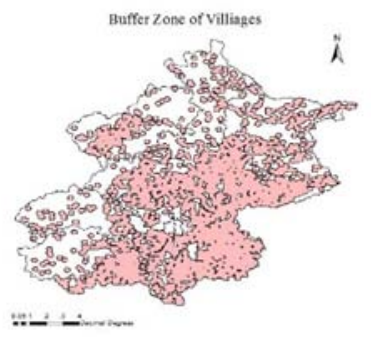

(A)

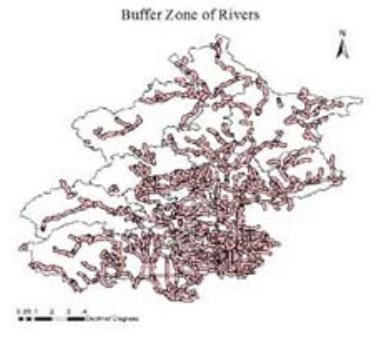

(B)

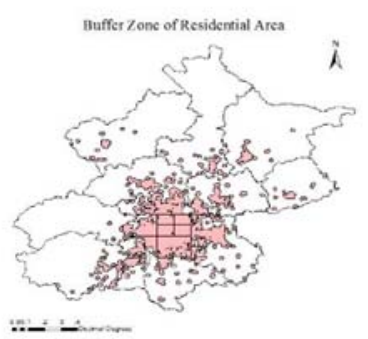

(C)

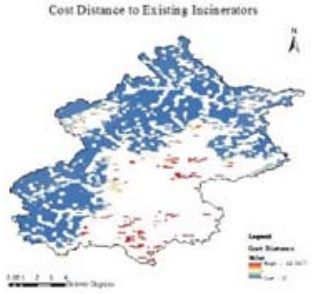

(D)

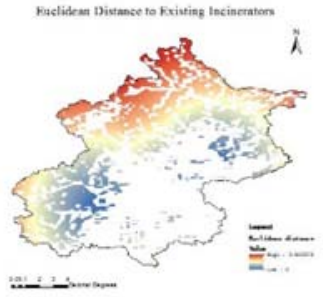

(E)

Fig.2 Five cost analysis results about environmental and health, transportation and operation costs are presented.

(2) Transportation Cost Analysis

There are now 16 districts in Beijing, the geometric center of each district is considered as the starting point for each district's garbage transport. As the amount of garbage generated is directly related to population density, raster data of population density of Beijing is used for cost distance calculation and transportation cost assessment. Cost distance analysis which is used to calculate the least cost weighted by a cost raster is a widely-used modelling tool. In cost distance models, a cost surface refers to an accumulative cost, which depends on various parts, that involves in the model [15]. As density of population (Fig.1 (D)) is the key factor affecting the amount of garbage generated in nearly approximate economic levels, it is assumed that the amount of municipal waste produced in each district is only related to population density. Geometric center of each district is used to value the distance between the site selected and each district of Beijing.

(3) Operating Cost Analysis

Build-Operate-Transfer, which is known as BOT, is a normal way for the operation of MWIs of China. It refers to the way that the government authorizes the entity to raise funds to design, build and operate a project before it can be handed over to the government. Because of the management model 
of BOT, specific operating costs cannot be taken into account easily. Evaluation of the distance between existing waste incineration plants and the site selection of the new ones is used as an alternative. Euclidean distance based models can make suitable decisions in layers with regular paths [16]. In this study, the relations between the siting of new MWIs and the built ones is measured by Euclidean distance, and reclassified into 5 categories (fig.2(C)).

(4) Geometric Analysis Integration

As we have two layers resulting above, using a grid calculator, the results of the reclassification are calculated at a ratio of 7:3. Finally, the results found in the raster layer is reclassified to make the results more intuitive. The complete workflow implemented in the model is shown in fig.3. The final raster layer generated by the model is added to an ArcGIS project to make the results visually for completely geometric analysis and advisable decisions.

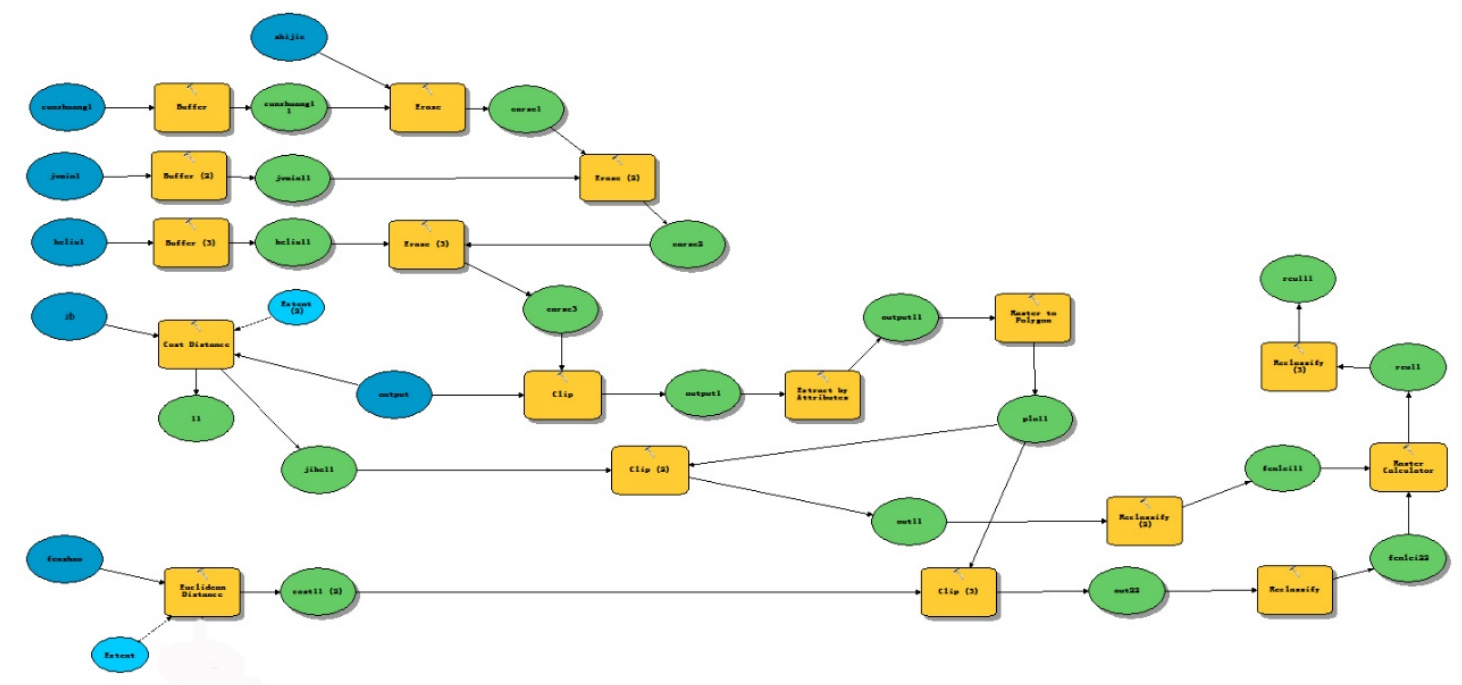

Fig.3 The model established in this paper using ArcGIS. Operations implemented in the model that correspond to some ArcGIS tools (buffer, reclassify, erase, extract by attributes and raster calculator) are represented by orange rectangles. Green circles show the output layers of each steps and the yellow ones refer to the condition applied to the model.

\section{Results and Conclusion}

The location reasonable for waste incineration plants are shown in fig.4 (A), pink areas in it represent the right place for construction, afterwards, it is reclassified on the basis of the transportation cost and the operation cost (fig.4(B)), where the pink area with the class " 5 " refers to the best place for location. The larger the numerical value after reclassification, the more suitable for site selection. As shown in fig.4(C), incinerator D (showed in the red circle) is preferred among the all 8 incinerators as the aspects above are taken into consideration.

In this work, a model to automatize the site selection process has been developed and implemented in ArcGIS. An example of the case city has been used to validate the model of its use in site selection. The application of the model built presents some advantages. It reduces the time spending on performing the site selection analysis and prevents some human errors of the evaluation. Furthermore, the model is easily applied and the implementation cost is low both in resources and time because only basic data and a few minutes of system calculation are needed. For these reasons, the model presented in this research is effective and satisfactory, and could be used to help regulators to select suitable site successfully. 


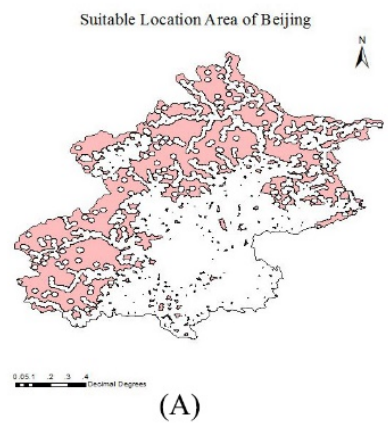

(A)

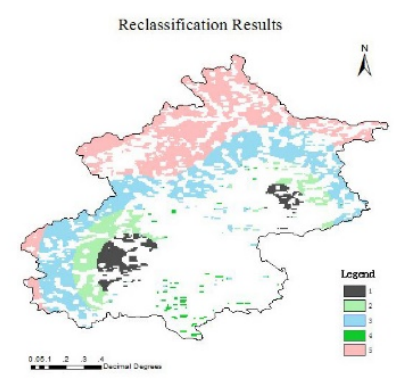

(B)

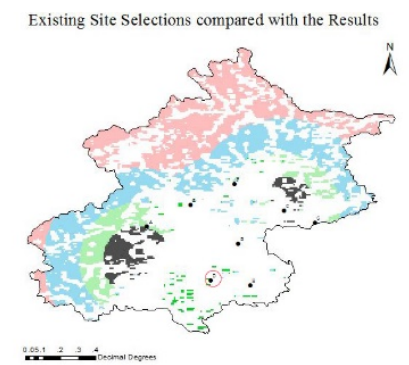

(C)

Fig.4 Reclassifications and final results of the model of the case city.

\section{Discussions}

Using model builder can analyze the spatial data quickly and easily that it becomes a handy tool for researchers from other field or government regulators for data processing and analysis including site selections. Nevertheless, because of the particularity of Beijing as the capital of China, a part of the food and water consumed by the residents of Beijing comes from Hebei province. Therefore, there might be some errors as only conditions of Beijing are taken into consideration. In addition, the environmental risk of atmospheric pollutants which are affected by terrain, weather and other factors, it's difficult (if not impossible) to put every possible factor into the model, therefore, in the actual applications, the model should be modified by specific weather conditions and terrain data.

\section{Acknowledgments}

This research was supported by Research Foundation of Renmin University of China, 2017 (NO.17XNH031)

\section{References}

[1]. Hu H, Li X, Nguyen A, Kavan P. International Journal of Environmental Research and Public Health (IJERPH), 2015, 12(7):7593-7614.

[2]. Jones P H, Gerlache J, Marti E, Mischer G, Scherrer M. Chemosphere, 1992 , 26 (8) :1491-1497, 1993.

[3]. Hsu S. The Social Science Journal (The Social Science Journal), 2006, 43(3):453-459.

[4]. Kogevinas M. Human Reproduction Update, 2001 , 109 (S103) :331-339, 2001.

[5]. Kim S, Moon H. Toxicology and Environmental Health Sciences, 2013 , 5 (3) :155-162, 2013.

[6]. Shen H, Guan R, Ding G, Chen Q, Lou X, Chen Z, Zhang L, Xing M, Han J, Wu Y. Science of The Total Environment(Science of The Total Environment), 2017, 574:120-127.

[7]. Murray A, Tong D, Kim K. International Regional Science Review, 2010 , 33 (2) :115-133, 2010.

[8]. Church R. Elsevier Science Ltd. , 2002 , 29 (6) :541-562, 2002.

[9]. Spaulding B, Cromley R. 2007.

[10]. Suárez-Vega R, Santos-Peñate D, Dorta-González P, Rodríguez-Díaz M. Applied Geography, 2011, 31 (1) :282-291, 2011.

[11]. Fernandez P, Moya-Delgado S. Environmental Modelling \& Software (Environmental Modelling \& Software), 2017, 92:119-124.

[12]. Zhang J. Applied Mechanics \& Materials, 2012, 170-173:2823-2826, 2012.

[13]. Chakravarty S. Journal of Economic Surveys, 1988, 2 (2) :177-181, 1988.

[14]. Berliant M, Peng S, Wang P. Journal of Economic Theory, 2002, 104 (2) :275-303, 2002. 
[15]. Siljander M, Venäläinen E, Goerlandt F, Pellikka P. Applied Geography, 2015 , 57 :54-70, 2015.

[16]. Mesquita D, Gomes J, Junior A, Nobre J. Neurocomputing , 2017 , 248 :11-18, 2017. 